RASĀYAN J. Chem.

Vol. 14 | No. 2 |684-690| April - June | 2021 ISSN: 0974-1496 | e-ISSN: 0976-0083 | CODEN: RJCABP http://www.rasayanjournal.com http://www.rasayanjournal.co.in

\title{
COLORIMETRIC PAPER-BASED DEVICE BY ENZYMATIC REACTION FOR DETECTING ALLOPURINOL IN TRADITIONAL MEDICINE
}

\author{
Rimadani Pratiwi ${ }^{\bowtie}$, Hanun Nabila, Febrina Amelia Saputri \\ and Rina Fajri Nuwarda
}

Department of Pharmaceutical Analysis and Medicinal Chemistry, Faculty of Pharmacy, Universitas Padjadjaran, Jatinangor, 45363, Indonesia

${ }^{\square}$ Corresponding Author: rimadani.pratiwi@unpad.ac.id

\begin{abstract}
The paper-based device for allopurinol detection was developed by an enzymatic reaction. The concept is that allopurinol will act by blocking the xanthine oxidase enzyme to produce uric acid and $\mathrm{H} 2 \mathrm{O} 2$, resulting in a color change from purple to pale purple until it is colorless. The concept was proofed by spectrophotometry and was applied in four types of filter paper including Whatman Qualitative No. 1, No. 4, and No. 6, and Whatman 1 chromatography. The application of this system was observed using ImageJ analysis. The performance of the paper reveals that each Whatman has different characteristics with LOD and LOQ range were 1.62-2.24 ppm and 4.91-6.80 ppm, respectively. The stability study shows that all of the paper was stable for 3 days both at room temperature (around $24^{\circ} \mathrm{C}-26^{\circ} \mathrm{C}$ ) and $4^{\circ} \mathrm{C}$. The presence of another drug like paracetamol did not prevent allopurinol detection. The real traditional medicine sample was also analyzed to confirm the applicability of this paper, and the result showed good agreement with spectrophotometry data.
\end{abstract}

Keyword: Allopurinol, Paper-based Analytical Device, Colorimetric, Traditional Medicine

RASĀYAN J. Chem., Vol. 14, No.2, 2021

\section{INTRODUCTION}

Jamu is a traditional herbal medicine prepared using plant extracts or herbal combinations. ${ }^{1}$ In the Indonesian community, particularly in rural and urban areas, traditional herbal medicine (Jamu) is used to treat some diseases or to maintain health. ${ }^{2}$ Since the consumption of Jamu has increased, some of the illegal manufacturers added chemical drugs to certain herbal medicine to enhance the therapeutic effect and increase the sales revenue. The Indonesian government has a regulation that Jamu should not contain synthetic chemicals or medicinal isolation results. ${ }^{3}$ The Food and Drug Administration in Indonesia issued a press release regarding a chemical drug that is usually added to Jamu, including allopurinol. Monitoring allopurinol in traditional medicines is important to control the acute adverse reactions of allopurinol that include diarrhea, drug fever, hematological abnormalities, etc. ${ }^{4}$

Allopurinol, a xanthine oxidase inhibitor, is a uricostatic gout drug used to reduce blood uric acid levels. ${ }^{5}$ Gout is caused by a high level of uric acid in the blood signed by crystal formation in the joint. ${ }^{6}$ Uric acid is produced by hydroxylation of hypoxanthine to xanthine and xanthine to uric acid catalyzed by xanthine oxidase (XO). ${ }^{7} \mathrm{XO}$ inhibitor has an important role to control uric acid production such as allopurinol that has been widely used for the treatment of gout. ${ }^{8}$ Uncontrolled consumption of allopurinol will cause some adverse reactions like diarrhea and hematological abnormalities. ${ }^{4}$ Therefore, to control the potential toxicity of allopurinol, monitoring allopurinol in Jamu is important.

Spectrophotometric and high-performance liquid chromatography are several analytical methods that are widely used for allopurinol detection. ${ }^{9,10}$ Although both methods are sensitive and selective, they require expensive instruments and cannot be applied for on-site analysis. Recently, the paper-based analytical device has received considerable attention as a tool for sample analysis owing to its simplicity, low cost, and easy usability. ${ }^{11-13}$ The paper-based device for drug detection has been developed. ${ }^{14-17}$ The most common detection technique used is the colorimetric method ${ }^{18}$ owing to its simplicity, visual readout, and fast analysis of chemical or enzymatic reactions to produce a different color. ${ }^{19,20}$ Previously, a paper-based 
RASĀYAN J. Chem.

Vol. 14 | No. 2 |684-690| April - June | 2021

analytical device for allopurinol detection in herbal medicine has been developed using a colorimetric reagent. ${ }^{21}$ Allopurinol will be detected based on the reaction of the colorimetric reagent with a functional group of allopurinol compounds. This system seems to be less selective since many compounds have the same functional group as allopurinol. In the current research, an enzymatic reaction was chosen as a reagent to improve the selectivity of the system since the colorimetric reagent detects a specific functional group in all compounds. Meanwhile, in this enzymatic reaction, it can only react with a compound with xanthine functional group such as allopurinol.

In this study, the paper-based device for allopurinol detection in Jamu was developed based on enzymatic reaction. Allopurinol is an XO inhibitor can be detected by an enzymatic reaction. XO assay kit was used as an enzymatic reagent to detect allopurinol. $\mathrm{XO}$ catalyzed the oxidation of hypoxanthine to xanthine and xanthine to uric acid. ${ }^{22}$ During this reaction, superoxide anion radicals and $\mathrm{H}_{2} \mathrm{O}_{2}$ are formed ${ }^{23}$ resulting in uric acid, and $\mathrm{H}_{2} \mathrm{O}_{2}$ is produced at the end of the reaction. $\mathrm{H}_{2} \mathrm{O}_{2}$ will react with the fluorescent peroxidase substrate on the XO assay kit resulting in a color change (purple) and can be observed at $570 \mathrm{~nm}$. If the allopurinol is present, they will compete with xanthine to bind with XO resulting in little to no color change. This concept was run first by spectrophotometry and was then continued to apply in various Whatman filter papers including Whatman No.1(W1), No.4(W4), and No. 6(W6) and Whatman 1 chromatography (WChr). The performance of the paper-based device is also demonstrated and shows that this platform could be employed for detecting allopurinol in Jamu.

\section{EXPERIMENTAL}

\section{Materials}

All chemicals used were of analytical grade and were used without further purification. All chemicals were obtained from the official distributor of Indonesia. In this experiment, commercially available XO assay kits were used for allopurinol detection (Sigma-Aldrich Cat no.: MAK078). XO microbial was purchased from Sigma-Aldrich (Cat no. X2252). Allopurinol was obtained from Nanjing Pharma Chemical Plant. W1, W4, W6, and WChr filter paper were purchased from GE Healthcare. Hydrochloric acid and sodium hydroxide were obtained from Merck.

\section{Color Change Analysis Using Absorbance}

To proof, the concept that the intensity of color will decrease in the presence of allopurinol, a variation concentration of allopurinol was added to the XO assay kit. Protocols from the supplier of the XO assay kit were applied step by step (Sigma-Aldrich, Cat no.: MAK078). Briefly, various concentrations of allopurinol were added to the reaction mix solution (as a protocol) in a 96-well plate and allowed to react for $25 \mathrm{~min}$. The absorbance was measured at $570 \mathrm{~nm}$ using UV-Visible spectrophotometer Analytik Jena SPECORD 200 using a $1.0 \mathrm{~cm}$ quartz cell.

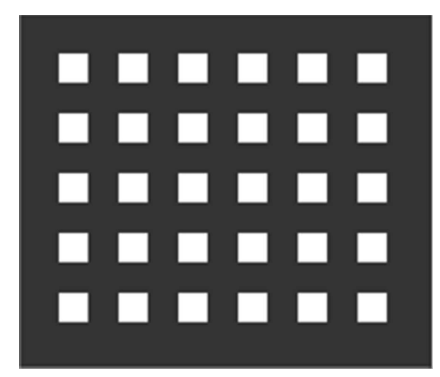

Fig.-1: Design of the Paper-based Device

\section{Design and Operation of the Paper-based Device}

$\mathrm{W} 1, \mathrm{~W} 4, \mathrm{~W} 6$, and $\mathrm{WChr}$ were cut into $0.5 \mathrm{~cm} \times 0.5 \mathrm{~cm}$ pieces. The backside of the piece of paper was sealed with packing tape to prevent the reagent from leaking out underneath the paper. Then, the paper was attached to the black paper background using double tape, as shown in Figure 1. The piece of paper was added with $10 \mu \mathrm{L}$ of reagent mix solution containing $4 \mu \mathrm{L}$ of XO microbial, $4 \mu \mathrm{L}$ of XO assay buffer, and $2 \mu \mathrm{L}$ of $\mathrm{XO}$ enzyme mix, and then the paper was dried at room temperature (around $24^{\circ} \mathrm{C}-26^{\circ} \mathrm{C}$ ). In using this device, $10 \mu \mathrm{L}$ of the sample solution that contains $2 \mu \mathrm{L}$ of XO substrate mix, $2 \mu \mathrm{L}$ of fluorescent 
RASĀYAN J. Chem.

Vol. 14 | No. 2 |684-690| April - June | 2021

peroxidase substrate, $5 \mu \mathrm{L}$ of allopurinol, and $1 \mu \mathrm{L}$ of XO assay buffer was added to the paper and was allowed $30 \mathrm{~min}$ to saturate and react with the reagent on the device. The devices were scanned using Scanner on HP LaserJet M1132 MFP and then the images were analyzed using ImageJ software by the grayscale method.

\section{Color Change Analysis}

\section{RESULTS AND DISCUSSION}

Before designing the paper-based device, a substrate competition assay in solution between xanthine and allopurinol was studied to determine that the color intensity will decrease in the presence of allopurinol. Various concentrations of allopurinol $0.01,0.1,1,10$, and $100 \mathrm{ppm}$ were added to the mix solution and react a different time, obtaining the graph in Figure 2. One unit of the $\mathrm{XO}$ enzyme will catalyze the oxidation of xanthine resulting in $1 \mu$ mole uric acid and $\mathrm{H}_{2} \mathrm{O}_{2}$. The $\mathrm{H}_{2} \mathrm{O}_{2}$ reacts with the fluorescent peroxidase substrate showing purple color, this indicates that uric acid is formed. XO inhibitor, such as allopurinol, acts by blocking the biosynthesis of the uric acid through the interaction at the purine binding site in the body. ${ }^{24,25}$ This will cause the $\mathrm{H}_{2} \mathrm{O}_{2}$ production to decrease linearly with the absorbance resulting in a color change from pale purple to colorless. As shown in Fig.-2, the longer reaction time produces more $\mathrm{H}_{2} \mathrm{O}_{2}$ (more uric acid), and the result demonstrated that $\mathrm{XO}$ will choose to react with allopurinol compared to xanthine, leading to less color change.

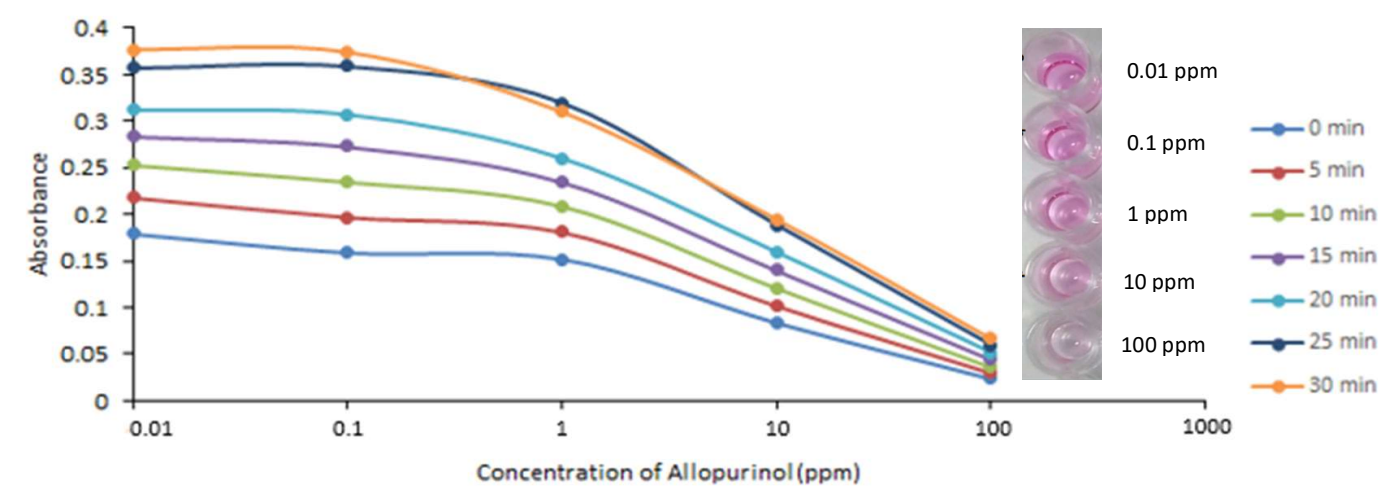

Fig.-2: Color Change Analysis to Demonstrate the Less Color Change resulted in the Presence of Allopurinol

\section{Design and Operation of the Paper-based Device}

The color changes from purple to colorless when the allopurinol presence in the XO assay kit solution makes the solution viable to be applied in the paper device. To apply this concept in the paper, the XO substrate is not added to the reagent mixture but is added to the sample mixture. This is intended to allow the competition between XO substrate and allopurinol. If the XO substrate is present in the reagent mixture and is added on the paper early, the purple color will form indicating that the XO substrate has reacted with the XO enzyme. When the sample containing allopurinol was added to the paper, the color will not change from pale purple to colorless because the XO enzyme has completely reacted, and allopurinol cannot block the reaction.

The paper device was designed simply by cutting the paper in a rectangular shape; the use of an application or software to design the device was not necessary. The devices were made using W1, W4, W6, and WChr filter paper. Each paper has a different characteristic, especially the pore size. W6 has smaller pores $(3 \mu \mathrm{m})$ relative to other paper and W4 has the biggest pores (20-25 $\mu \mathrm{m})$. As shown in Fig.-3, W6 performed better in color intensity relative to others. This result supports the hypothesis that smaller pores or slower flow will increase reaction efficiency resulting in a more noticeable color change ${ }^{16}$.

\section{Performance of the Paper-based Device}

To observe the performance of the paper, calibration curves were also generated for four different types of paper in the concentration of allopurinol 1, 2, 4, 6, 8, and $10 \mathrm{ppm}$. As shown in Figure 4, a linear trend between allopurinol concentration and color intensity was observed in each variation of paper. The results 
RASĀYAN J. Chem.

Vol. 14 | No. 2 |684-690| April - June | 2021

show a negative trend because we are measuring the color intensity of the $\mathrm{H}_{2} \mathrm{O}_{2}$ as a result of the enzymatic reaction between the $\mathrm{XO}$ enzyme and the $\mathrm{XO}$ substrate. The more allopurinol present in the sample, the reaction between $\mathrm{XO}$ enzyme and $\mathrm{XO}$ substrate will cause the fewer $\mathrm{H}_{2} \mathrm{O}_{2}$, resulting in lower purple intensity. Limit of Detection (LOD) and Limit of Quantification (LOQ) was measured to get the analytical performance of this device. The result showed that W4 has the lowest LOD and LOQ compare to other papers. W6 and WChr showed similar LOD and LOQ.

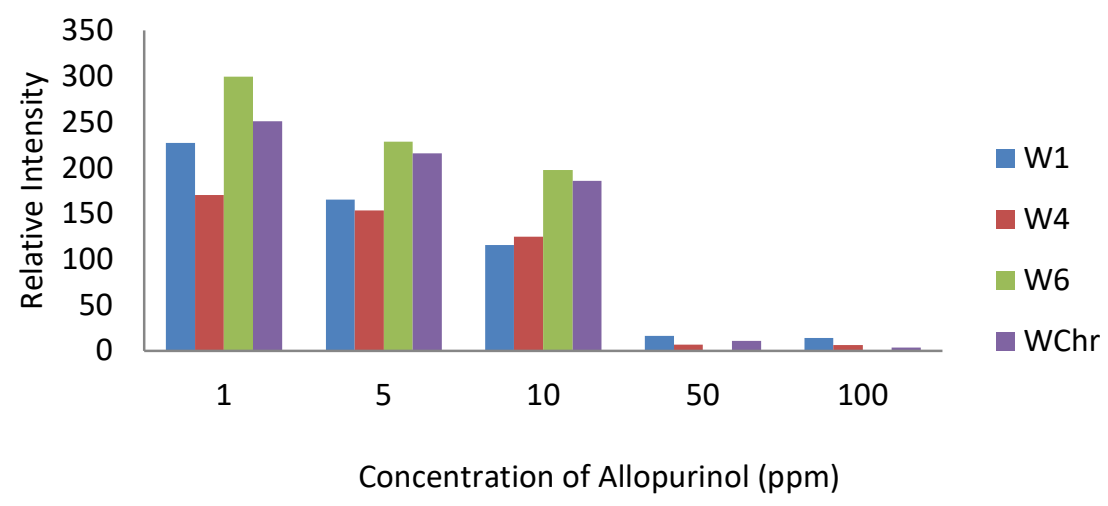

Fig.-3: The Color Intensity of Allopurinol in a Different Types of Paper

W1

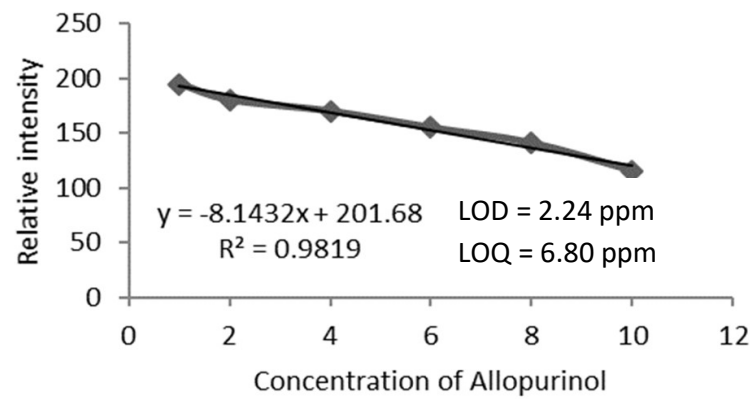

W6

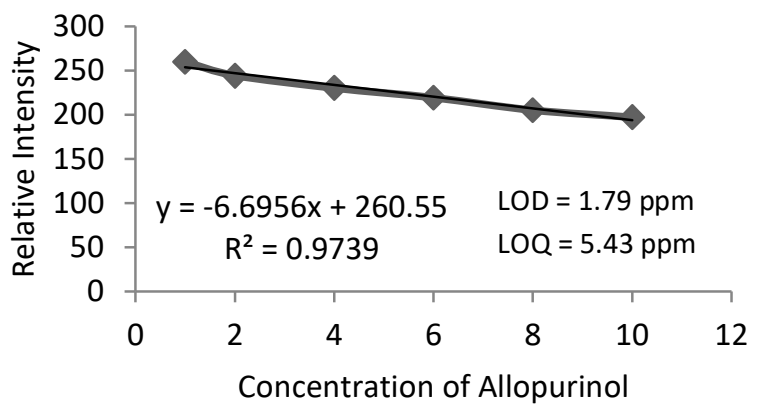

W4

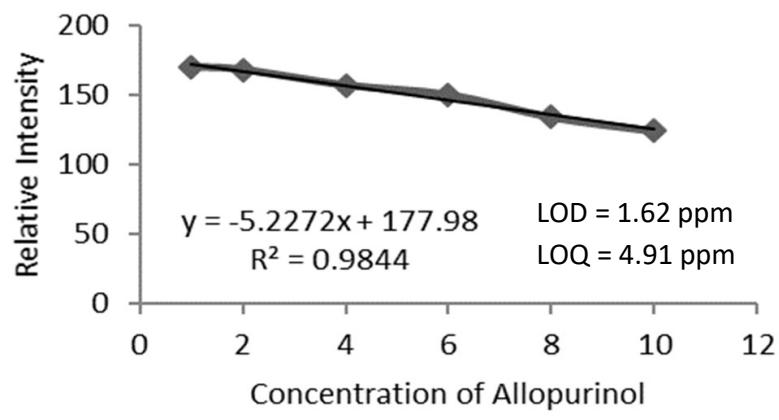

WChr

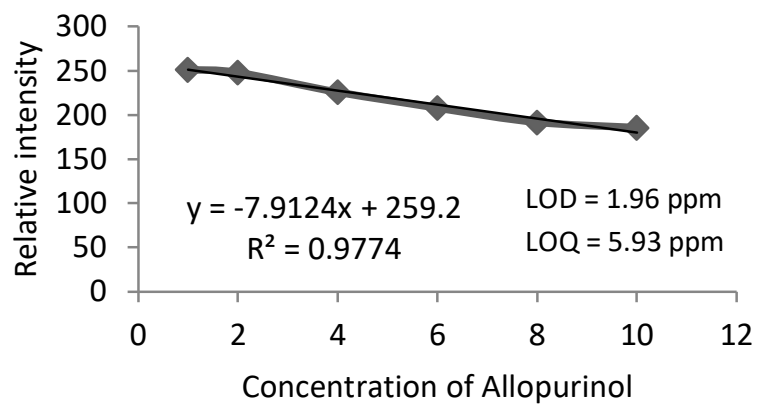

Fig.-4: Calibration Curve of Allopurinol in Paper-based Device

The stability of the paper was observed by adding the reagent mix on the piece of paper and dried at room temperature. The paper stored in light protected at room temperature (around $24^{\circ} \mathrm{C}-26^{\circ} \mathrm{C}$ ) and $4{ }^{\circ} \mathrm{C}$ and light protected. The purpose of this study is to get a lifetime of paper that can still give a good response. As shown in Fig.-5, on Day 1 all paper still gives the best response for all of the paper then on Day 2 the less color intensity was observed. On Day 3, at room temperature, the response is very weak until Day 4 all of the papers did not give the response in the presence of allopurinol almost all the paper did not respond to 
RASĀYAN J. Chem.

Vol. 14 | No. 2 |684-690| April - June | 2021

the allopurinol. Consequently, the stability of the regent mix solution on paper at room temperature is 3 days. Furthermore, at $4^{\circ} \mathrm{C}$ the color intensity of the paper decreased gradually and tends to stable after 3 days.

A

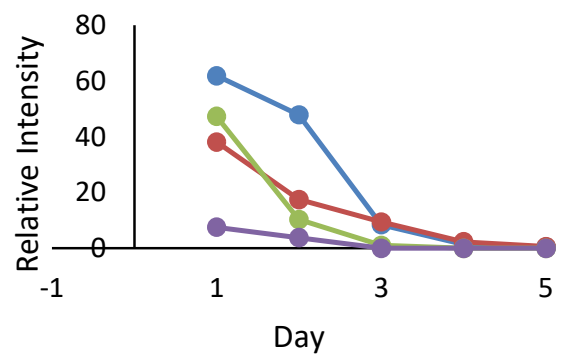

B

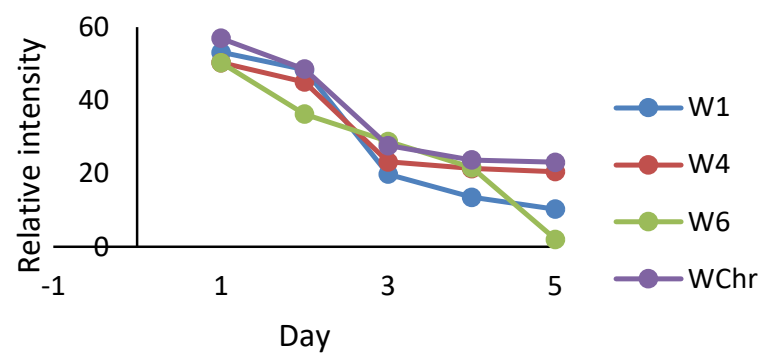

Fig.-5: Stability Study of the Paper-based Device in the Presence of Allopurinol (A) at room temperature, around $24^{\circ} \mathrm{C}-26^{\circ} \mathrm{C}(\mathrm{B})$ at $4^{\circ} \mathrm{C}$

Another drug usually added in Jamu is used as a treatment for gout. Therefore, the selectivity test of the paper must be conducted to verify the paper still works in the presence of other drugs commonly found in Jamu samples for gout, such as paracetamol. In this assay, the same concentration of paracetamol and allopurinol (5 ppm) was tested. Paracetamol solution in ethanol $96 \%$ was mixed with sample solution and then added into the paper. Figure- 6 shows that in the presence of paracetamol, the color intensity of paper is higher than that of allopurinol. It is described that the enzymatic reactions are not inhibited in the presence of paracetamol resulting in higher color intensity.

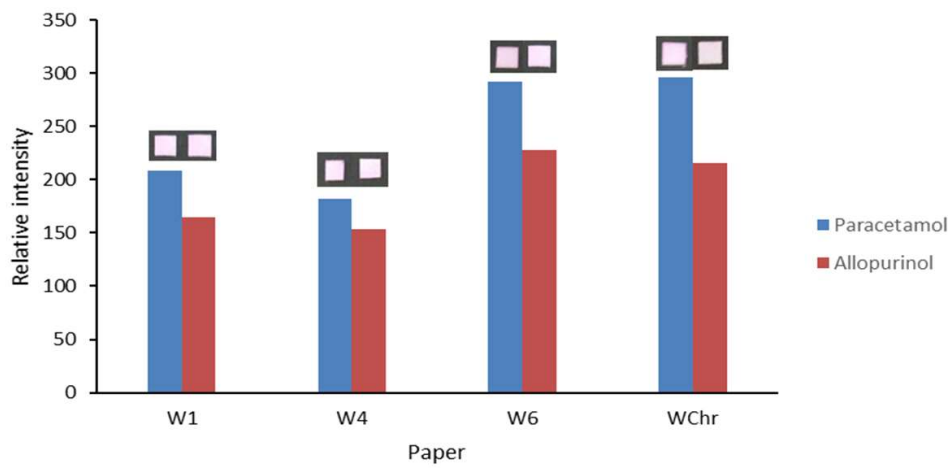

Fig.-6: Selectivity Study of the Paper-based Device

\section{Application of Paper-based Device for Real Sample Analysis}

To demonstrate the applicability of this paper for real sample analysis, a sample of Jamu was analyzed using spectrophotometry UV-Visible and our paper-based device. The sample was prepared as a reported literature procedure ${ }^{21}$. The result shows that allopurinol was not detected in the sample by using spectrophotometry. The sample was then prepared by the standard addition method and spiked with $5 \mathrm{ppm}$ of allopurinol. The results are summarized in Table-1 showing good agreement between the paper-based devices with spectrophotometry data. This suggests that the paper-based method can quantify allopurinol in the real sample.

Table-1: Recovery Test on the Determination of Allopurinol in the Sample by PAD Spectrophotometry UV ( $\mathrm{n}=3)$

\begin{tabular}{|c|c|c|c|c|c|c|c|}
\hline \multirow[t]{2}{*}{ Sample } & \multicolumn{3}{|c|}{ Spectrophotometry } & \multicolumn{4}{|c|}{ Paper-based Device } \\
\hline & Added (ppm) & Found (ppm) & Recovery (\%) & Paper & Added (ppm) & Found (ppm) & Recovery (\%) \\
\hline \multirow{4}{*}{ Sample 1} & \multirow{4}{*}{5} & \multirow{4}{*}{$4.93 \pm 0.003$} & \multirow{4}{*}{98.67} & W1 & 5 & $4.83 \pm 0.04$ & 96.68 \\
\hline & & & & W4 & 5 & $4.92 \pm 0.19$ & 98.52 \\
\hline & & & & W6 & 5 & $5.03 \pm 0.04$ & 100.67 \\
\hline & & & & WChr & 5 & $5.38 \pm 0.02$ & 107.71 \\
\hline
\end{tabular}


RASĀYAN J. Chem.

Vol. 14 | No. 2 |684-690| April - June | 2021

\begin{tabular}{|c|c|c|c|c|c|c|c|}
\hline \multirow{4}{*}{ Sample 2} & \multirow{4}{*}{5} & \multirow{4}{*}{$5.00 \pm 0.005$} & \multirow{4}{*}{100.19} & W1 & 5 & $4.93 \pm 0.04$ & 98.59 \\
\hline & & & & W4 & 5 & $4.88 \pm 0.10$ & 97.63 \\
\hline & & & & W6 & 5 & $5.08 \pm 0.05$ & 101.76 \\
\hline & & & & WChr & 5 & $5.19 \pm 0.03$ & 103.84 \\
\hline \multirow{4}{*}{ Sample 3} & \multirow{4}{*}{5} & \multirow{4}{*}{$4.96 \pm 0.005$} & \multirow{4}{*}{99.26} & W1 & 5 & $4.96 \pm 0.01$ & 96.68 \\
\hline & & & & W4 & 5 & $4.88 \pm 0.03$ & 98.52 \\
\hline & & & & W6 & 5 & $5.03 \pm 0.05$ & 100.67 \\
\hline & & & & WChr & 5 & $5.17 \pm 0.01$ & 107.71 \\
\hline \multirow{4}{*}{ Sample 4} & \multirow{4}{*}{5} & \multirow{4}{*}{$5.03 \pm 0.004$} & \multirow{4}{*}{100.55} & W1 & 5 & $4.98 \pm 0.03$ & 96.68 \\
\hline & & & & W4 & 5 & $4.91 \pm 0.05$ & 98.52 \\
\hline & & & & W6 & 5 & $5.06 \pm 0.04$ & 100.67 \\
\hline & & & & WChr & 5 & $5.17 \pm 0.01$ & 107.71 \\
\hline
\end{tabular}

\section{CONCLUSION}

A paper-based device for detecting allopurinol in traditional medicine has been developed based on enzymatic reaction. The device has a simple design and is easy to use for detecting allopurinol by colorimetric method. The performance of the paper-based device shows good sensitivity and selectivity. The developed paper-based device was also successful for the determination of allopurinol in Jamu samples, which shows a good agreement with spectrophotometric data. Each filter paper shows different characteristics; nevertheless, the paper-based device is potential for in-field allopurinol detection through an enzymatic reaction. This paper-based sensor offers new possibilities in the field of analysis of allopurinol in another sample.

\section{ACKNOWLEDGEMENT}

The authors acknowledge the financial support received from the Directorate of Higher Education Indonesia, for their support to facilitate this research.

\section{REFERENCES}

1. S. Riswan and H. Sangat-Roemantyo, South Paciflc Study, 23(1), 1 (2002).

2. H. J. Woerdenbag and O. Kayser, Journal of Herbal Medicine, 4(2), 51(2014), DOI:10.1016/j.hermed.2014.01.002

3. I. Dalli, D. Ramdhani, and A. N. Hasanah, Indonesian Journal of Chemistry, 17(1), 71(2017), DOI: $10.22146 /$ ijc. 23612

4. G. McInnes, D. Lawson, and H. Jick, Annals of the Rheumatic Diseases, 40(3), 245(1981), DOI: $10.1136 /$ ard.40.3.245

5. R. Seth, A. S. Kydd, R. Buchbinder, C. Bombardier, and C. J. Edwards, Cochrane Database of Systematic Reviews, 14(10), CD006077 (2014).

6. N. Schlesinger, Drugs, 64, 2399(2004), DOI:10.2165/00003495-200464210-00003

7. D. A. Kostić, D. S. Dimitrijević, G. S. Stojanović, I. R. Palić, A. S. Đorđević, and J. D. Ickovski, Journal of Chemistry, 2015, Article ID 294858 (2015), DOI:10.1155/2015/294858

8. T. M. Ngoc, N. M. Khoi, D. T. Ha, N. X. Nhiem, B. H. Tai, D. V. Don, H. V. Luong, D. C. Son, K. Bae, Bioorganic \& Medicinal Chemistry Letters, 22(14), 4625(2012), DOI:10.1016/j.bmcl.2012.05.051

9. W. S. Khayoon, M. Q. Al-Abaichy, M. Jasim, and M. A. Al-Hamadany, Journal of Physical Science, 19(2), 23(2008).

10. M. K. Reinders, L. C. Nijdam, E. N. V. Roon, K. L. L. Movig, T. L. T. A. Jansen, M. A. F. J. Laar, J. R. B. J. Brouwers, Journal of Pharmaceutical and Biomedical Analysis, 45(2), 312(2007), DOI:10.1016/j.jpba.2007.08.002

11. Y. Lin, D. Gritsenko, S. Feng, Y. C. Teh, X. Lu, and J. Xu, Biosensors and Bioelectronics, 83, 256 (2016), DOI:10.1016/j.bios.2016.04.061

12. D. M. Cate, J. A. Adkins, J. Mettakoonpitak, and C. S. Henry, Analytical Chemistry, 87(1), 19(2014), DOI: $10.1021 / \mathrm{ac} 503968 \mathrm{p}$

13. A. W. Martinez, S. T. Phillips, Z. Nie, C. Cheng, E. Carrilho, B. J. Wiley, G. M. Whitesides, Lab on a Chip, 10(19), 2499(2010), DOI:10.1039/c01c00021c 
RASĀYAN J. Chem.

Vol. 14 | No. 2 |684-690| April - June | 2021

14. E. Costa-Rama, H. Nouws, C. Delerue-Matos, M. Blanco-López, and M. Fernández-Abedul, Analytica Chimica Acta, 1074, 89(2019), DOI:10.1016/j.aca.2019.05.016

15. L. Y. Shiroma, M. Santhiago, A. L. Gobbi, and L. T. Kubota, Analytica Chimica Acta, 725, 44(2012), DOI:10.1016/j.aca.2012.03.011

16. K. E. Boehle, C. S. Carrell, J. Caraway, and C. S. Henry, ACS Sensors, 3(7), 1299(2018), DOI: 10.1021 /acssensors. 8 b00163

17. W. Liu, Y. Guo, H. Li, M. Zhao, Z. Lai, and B. Li, Spectrochimica Acta Part A: Molecular and Biomolecular Spectroscopy, 137, 1298(2015), DOI:10.1016/j.saa.2014.09.059

18. G. G. Morbioli, T. Mazzu-Nascimento, A. M. Stockton, and E. Carrilho, Analytica Chimica Acta, 970, 1(2017), DOI:10.1016/j.aca.2017.03.037

19. G. Sriram et al., TrAC Trends in Analytical Chemistry, 93, 212(2017), DOI:10.1016/j.trac.2017.06.005

20. L.-M. Fu and Y.-N. Wang, TrAC Trends in Analytical Chemistry,107, 196(2018), DOI: $10.1016 /$ j.trac.2018.08.018

21. R. Pratiwi, R. N. Septyani, R. Febriany, F. A. Saputri, and R. F. Nuwarda, International Journal of Analytical Chemistry, 2019, Article ID 4682839(2019), DOI:10.1155/2019/4682839

22. F. Candan, Journal of Enzyme Inhibition and Medicinal Chemistry, 18(1), 59(2003), DOI: $10.1080 / 1475636031000069273$

23. E. E. Kelley, N. K. Khoo, N. J. Hundley, U. Z. Malik, B. A. Freeman, and M. M. Tarpey, Free Radical Biology and Medicine, 48(4), 493(2010), DOI:10.1016/j.freeradbiomed.2009.11.012

24. R. Hille and V. Massey, Pharmacology \& Therapeutics, 14(2), 249(1981), DOI:10.1016/0163$7258(81) 90063-2$

25. T. R. Hawkes, G. N. George, and R. Bray, Biochemical Journal, 218(3), 961(1984), DOI: $10.1042 / \mathrm{bj} 2180961$

[RJC-6126/2020] 